EMITTER International Journal of Engineering Technology ISSN: 2443-1168, Vol. 8, No. 2, December 2020, pp. 389 406

DOI : $10.24003 /$ emitter.v8i2.532

\title{
Load Frequency Control of Three area Multi-Unit Deregulated Power System with FOSMC and Performance analysis using Regulation constant
}

\author{
Kurakula Vimala Kumar*, 1, G.Sritej², V.Ganesh ${ }^{3}$ \\ ${ }^{1}$ Assistant Professor, Department of Electrical and Electronics Engineering \\ 2P.G Scholar, Department of Electrical and Electronics Engineering \\ ${ }^{3}$ Professor, Department of Eleectrical and Electronics Engineering \\ JNTUA College of Engineering Pulivendula, A. P, INDIA-516390. \\ E-mail: princevimal81@gmail.com ${ }^{1,}$; sritej01@gmail.com ${ }^{2}$ \\ *Corresponding author: princevimal81@gmail.com
}

Received July 16, 2020; Revised November 5, 2020; Accepted December 5, 2020

\begin{abstract}
This paper presents three area multi-unit Deregulated Power System (DPS) for Load Frequency Control (LFC) using Fractional Order Sliding Mode Controller (FOSMC) along with Thyristor Controlled Phase Shifters (TCPS) and Superconducting Magnetic Energy Storage (SMES) combination. The FOSMC can be used to overcome nonlinearities and uncertainties of the system for bilateral and unilateral transactions under different Step Load Perturbations (SLP's). The deregulated power system performance is analyzed for different Regulation constants (R) such as 1.8, 2.4 and 3.0. For stabilization of oscillations in frequency and to stabilize the deregulated power system dynamically for different SLPs, TCPS is incorporated with the tie line in series and SMES is used as an energy storage unit. The dynamic responses of LFC problems have been simulated and analyzed with MATLAB/Simulink-based computer simulations. Further simulation results have also been tabulated as a comparative performance with respect to peak overshoot and settling time.
\end{abstract}

Keywords: Deregulated Power System, Load Frequency Control, Fractional Order Sliding Mode Controller, Thyristor Controlled Phase Shifters, Superconducting Magnetic Energy Storage, Bilateral, Unilateral, Step Load Perturbation, Regulation constant.

\section{INTRODUCTION}

This paper deals with how the dynamic performance of frequency change in control areas and power in tie line has improved for load frequency control in three area multi-unit power system in deregulated environment after employing Fractional Order Sliding Mode Control (FOSMC) along with Thyristor Controlled Phase Shifters (TCPS) and Superconducting Magnetic Energy Storage (SMES) combination for different Regulation constants(R) and for different Step Load Perturbations (SLPs). 


\section{RELATED WORKS}

\subsection{Analysis of Load Frequency Control (LFC) and Deregulated Power System (DPS)}

Load Frequency Control (LFC) problem in an integrated power grid is the most significant research context with a long history. On restructuring the power network, the entire Vertically Integrated Utility (VIU) is classified as Generation companies (GENCO's), Transmission companies (TRANSCO's), Distribution companies (DISCO's), as well as Independent System Operators (ISO's)[1,2]. A matrix called DISCO Participation Matrix (DPM) helps us to identify bilateral or unilateral transactions. Each element in the matrix represents contract participation factor (cpf). The DPM matrix with three area consisting of eight Gencos and eight Discos is defined as

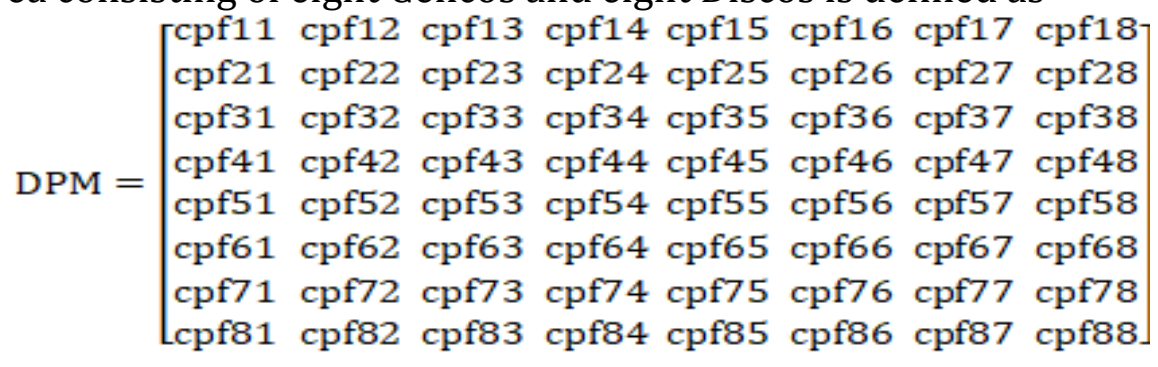

\subsection{Concept of Thyristor Controlled Phase Shifter (TCPS)}

The actual power flow can be regulated by Thyristor Controlled Phase Shifter (TCPS) with varying of relative phase angle between the system voltages to minimize frequency oscillations and also to increase the reliability of the power network[3,5,6]. Figure 1 showcases the simple diagram showing TCPS in series with that of the tie-line and a two-area interlinked power grid.

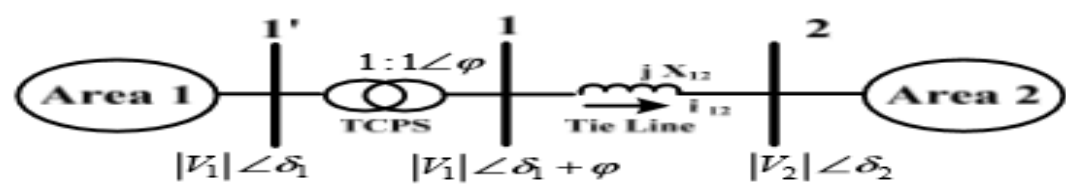

Figure 1: Schematic representation of TCPS in series with tie line for two-area control network

Figure 2 reveals the transfer function model of TCPS that is used as frequency regulator, is implemented in this work.

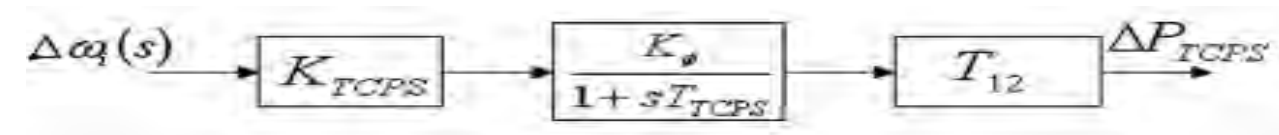

Figure 2: Detailed block diagram representation of TCPS unit

\subsection{Designing of Superconducting Magnetic Energy Storage (SMES) system}


The representation of SMES system is indicated in Figure 3. The SMES is known well as an active power source. As SMES operates very fast in dynamic conditions, it has a huge scope in LFC $[4,5]$.

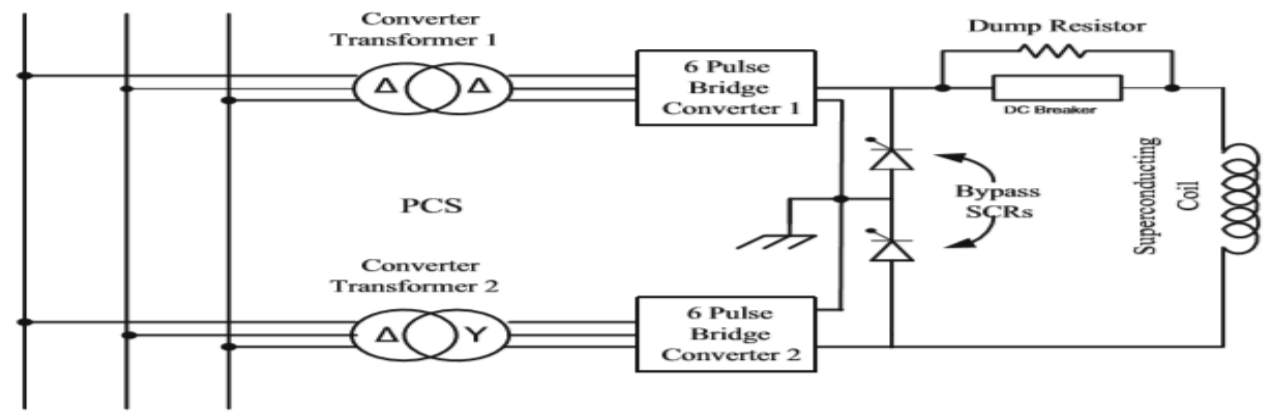

Figure 3: Configuration of SMES in power system

In the instance of a rapid rise in load demand, the energy stored in superconducting coil during the steady state operation would be supplied as an alternating current to the power grid through a line commutated converter. To reset the power grid to a new operating state, the governor and other control mechanisms will start operating, the coil current in SMES will set back to its normal value and performs similarly for decrease in load [6].

The SMES block diagram with transfer function strategy is shown in Figure 4 .

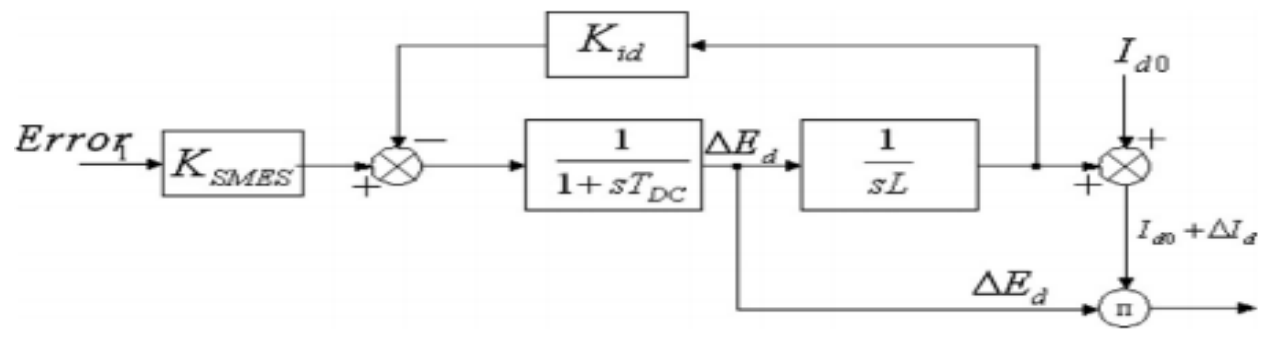

Figure 4: Block diagram representation of SMES unit

\subsection{Preliminaries of Fractional Order Sliding Mode Controller (FOSMC)}

The usefulness of the sliding mode controller in fractional order is that it stabilizes unstable non-linear systems with many inputs containing nonlinearities and uncertainties [7]. For uncertain nonlinear systems, the FOSMC guarantees the necessary situation of the sliding mode.

\subsubsection{Design of Fractional Order Sliding Mode Control (FOSMC)}

The control rules as well as the switching function are two key components regarded in SMC construction. The architecture of FOSMC practically relies on the configuration of the sliding surface with fractional order. The corresponding control rule is a sliding surface function.

$e(t)=A C E_{i}=B_{i} \Delta f_{\text {ierror }}+\Delta P_{\text {ierror }} \quad \mathrm{i}=1 ., 2, \ldots$

The sliding surface given as

$S=K_{0} e(t)+K_{1} D^{-\lambda} e(t)$ 
The equivalent control law (Ueq) is given as

$u_{e q}=K_{2} e(t)+K_{3} D^{1-\lambda} e(t)$

The switching control law is a function of Sign function

$$
u_{S W}=K_{4} D^{1-\lambda} \operatorname{Sign}(S)
$$

$\operatorname{Sign}(S)=\left\{\begin{array}{cc}1 & S>0 \\ 0 & S=0 \\ -1 & S<0\end{array}\right.$

The global control law $\left(\mathrm{ug}_{\mathrm{g}}\right)$ is a combination of equivalent control and switching law.

$$
\begin{aligned}
& u_{g}=u_{e q}+u_{s w} \\
& u_{g}=K_{2} e(t)+K_{3} D^{1-\lambda} e(t)+K_{4} D^{1-\lambda} \operatorname{Sign}(S)
\end{aligned}
$$

Where $\mathrm{K}_{1}, \mathrm{~K}_{2}, \mathrm{~K}_{3}, \mathrm{~K}_{4}$. are positive variables, $\mathrm{D}$ is Damping coefficient and $\mathrm{D}^{1-\lambda}$ is Fractional derivative operator.

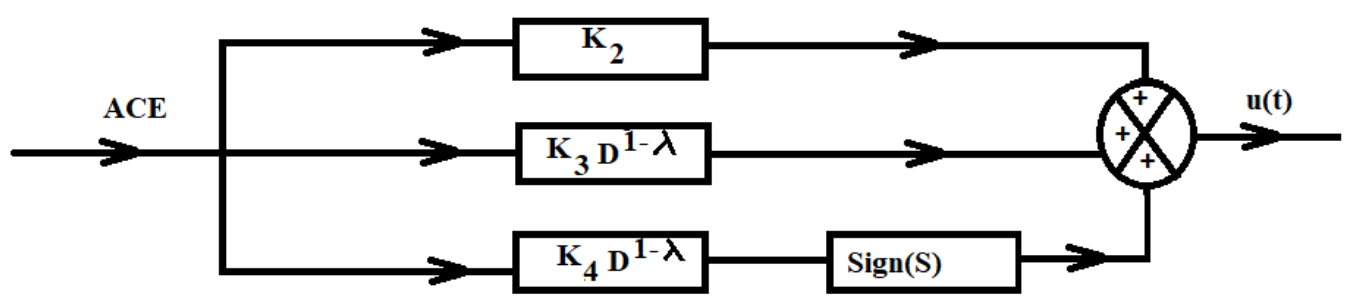

Figure 5: FOSMC representation for global rule enforcement

Figure 5 showcases the global rule enforcement representation of FOSMC and Figure 6 represents block diagram of FOSMC employed for Deregulated Power System.

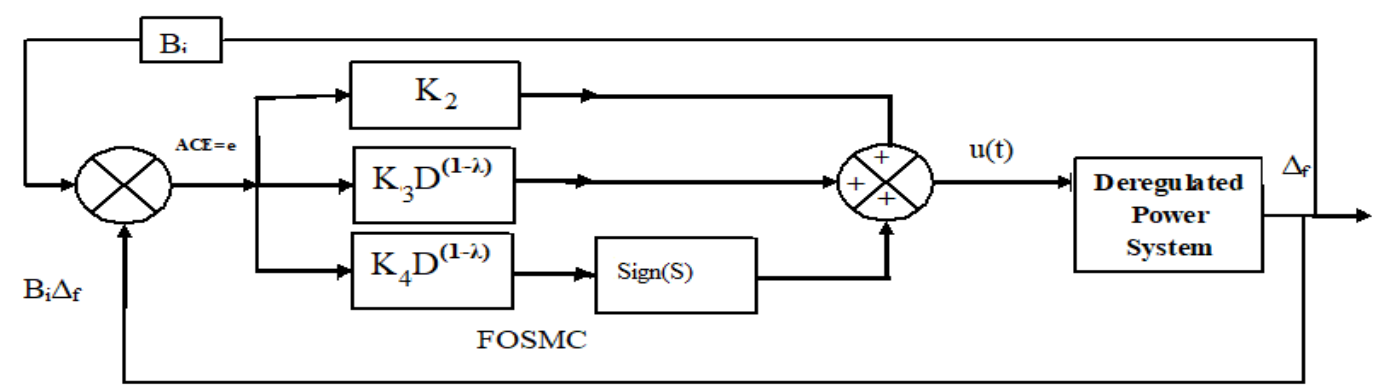

Figure 6: Block diagram layout of FOSMC control rule for DPS application

\subsection{Prominence of Regulation constant (R)}

Regulation constant $(\mathrm{R})$ can be given as ratio to change in frequency $(\Delta \mathrm{f})$ and change in generation $(\Delta \mathrm{Pg})$ contributed by the unit,

$$
R=\frac{|\Delta \mathrm{ff}|}{|\Delta \mathrm{Pg}|} \mathrm{Hz} / \mathrm{MW}
$$

The change in generation $(\Delta \mathrm{Pg})$ under steady state due to change in frequency $(\Delta \mathrm{f})$ is given as shown in equation (10) 


$$
\Delta \mathrm{Pg}=\frac{-\Delta f}{R} \mathrm{MW}
$$

Negative sign in equation (10) indicates that there is decrease in generation due to increase in frequency of the system and vice versa. The change in generation $(\Delta \mathrm{Pg})$ under steady state due to change in frequency $(\Delta \mathrm{f})$ and change in command signal $(\Delta \mathrm{Pc})$ is given as shown in equation (11)

$$
\Delta \mathrm{Pg}=\Delta \mathrm{Pc}-\frac{\Delta f}{R} \mathrm{MW}
$$

Regulation constant(R) plays a vital role in turbine/generator speed controlling and Load Frequency Control (LFC) in generation systems. The permissible limits for Regulation constant(R) are 3\% to 6\%.

Based on regulation constant, speed governors in power system are classified into two types [8], they are

- If $\mathrm{R}=0 \%$ then it is Isochronous governor

- If $\mathrm{R} \neq 0 \%$ then it is Droop governor.

Example: Droop of 5\%, may indicate that

- A $5 \%$ change in frequency, means

- $50 \mathrm{~Hz} \times 0.05=2.5 \mathrm{~Hz}$

- For a 4-pole generator, $1500 \mathrm{rpm} \times 0.05=75 \mathrm{rpm}$

Figure 7 shows with droop of $5 \%$ graphically

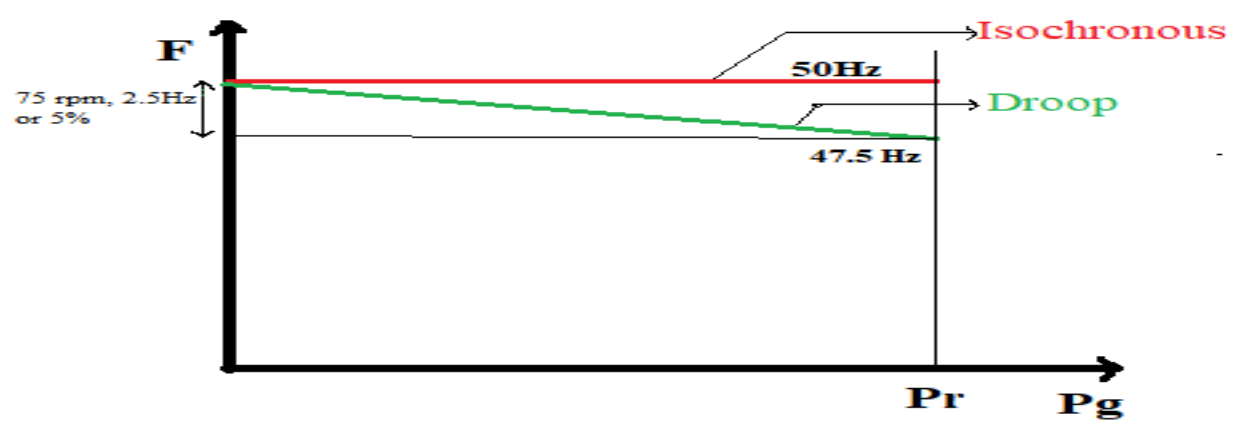

Figure 7: Illustrates Isochronous governor and Droop governor

\section{ORIGINALITY}

The FOSMC can be used to overcome nonlinearities and uncertainties of the system for bilateral and unilateral transactions under different Step Load Perturbation's (SLP's). The deregulated power system performance is analyzed for different Regulation constants (R) such as 1.8, 2.4 and 3.0. The dynamic responses of LFC problems have been simulated and analyzed with MATLAB/Simulink-based computer simulations. Further simulation results have also been tabulated as a comparative performance with respect to peak overshoot and settling time.

\section{SYSTEM DESIGN}

A three-area deregulated power system comprised with three single, multi-unit control areas, connected through two power lines called tie-lines, 
as shown in the Figure 8. First area includes thermal and hydro systems as GENCO-1 and GENCO-2, second area includes thermal, hydro and wind systems as GENCO-3, GENCO-4 and GENCO-5 and third area includes thermal, hydro and wind systems as GENCO-6, GENCO-7 and GENCO-8. First area as well as second area are linked by tie-line 1-2, in the same way that second area as well as third area are also linked by tie-line 2-3. TCPS is linked in series with each tie-line and SMES is integrated to the load points for each area can be seen in Figure8. FOSMC controller is being used in this study.

As far as now for experimental analysis three area deregulated power system with three single, multi-unit control areas was considered. Later for future scope with this as base, number of directions that this work can be extended as number of areas and tie lines can be increased, other different types of power generating units in each area can be employed, number of Disco's can be expanded, can also be analysed with different Area Participation Factors (APF's) and Contract Participation Factors (CPF's), FOSMC can be replaced by any modern advanced controller, analysis can be extended to contract violation, any further advanced FACTS devices can be employed to enhance the reliability of the power system.

\section{EXPERIMENT AND ANALYSIS}

Simulations are performed in MATLAB/Simulink environment under bilateral transaction and unilateral transaction scenarios under various operating conditions such as with Step Load Perturbations (SLP) of 1\% and $10 \%$ and with different regulation constants (R) of $1.8 \mathrm{~Hz} / \mathrm{p} . \mathrm{uMW}, 2.4$ Hz/p.uMW and $3.0 \mathrm{~Hz} /$ p.uMW. 


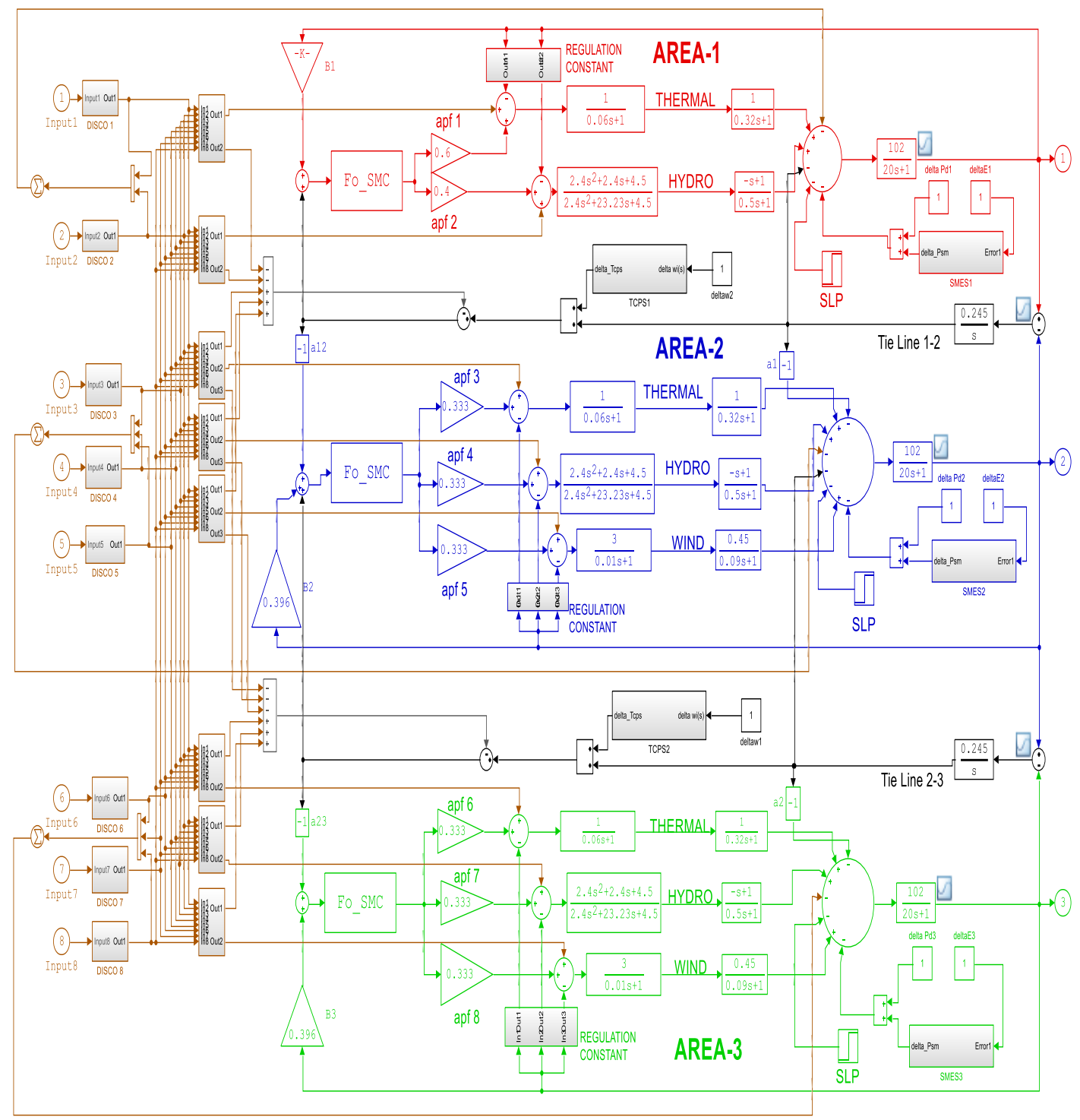

Figure 8: Simulation model of the three-area LFC multi-unit deregulated power system including combination of FOSMC and TCPS-SMES

\subsection{Scenario1: Considering bilateral transaction}

The DPM matrix for bilateral transaction is given as shown below

$\mathrm{DPM}=\left[\begin{array}{cccccccc}0.2 & 0.17 & 0.12 & 0.15 & 0.1 & 0.05 & 0.13 & 0.08 \\ 0.1 & 0.13 & 0.05 & 0.08 & 0.15 & 0.13 & 0.17 & 0.17 \\ 0.15 & 0.05 & 0.13 & 0.12 & 0.08 & 0.17 & 0.2 & 0.15 \\ 0.08 & 0.12 & 0.17 & 0.05 & 0.12 & 0.12 & 0.15 & 0.13 \\ 0.12 & 0.08 & 0.2 & 0.2 & 0.05 & 0.01 & 0.1 & 0.1 \\ 0.05 & 0.15 & 0.1 & 0.1 & 0.2 & 0.15 & 0.08 & 0.05 \\ 0.13 & 0.1 & 0.15 & 0.13 & 0.13 & 0.1 & 0.12 & 0.2 \\ 0.17 & 0.2 & 0.08 & 0.17 & 0.17 & 0.2 & 0.05 & 0.12\end{array}\right]$

The simulation results of divergence in frequency of control areas and tie-lines power divergence for different regulation constants of different Step 
load perturbations (SLP's) are shown below.

CASE A: Step load perturbations (SLP) of 1\%

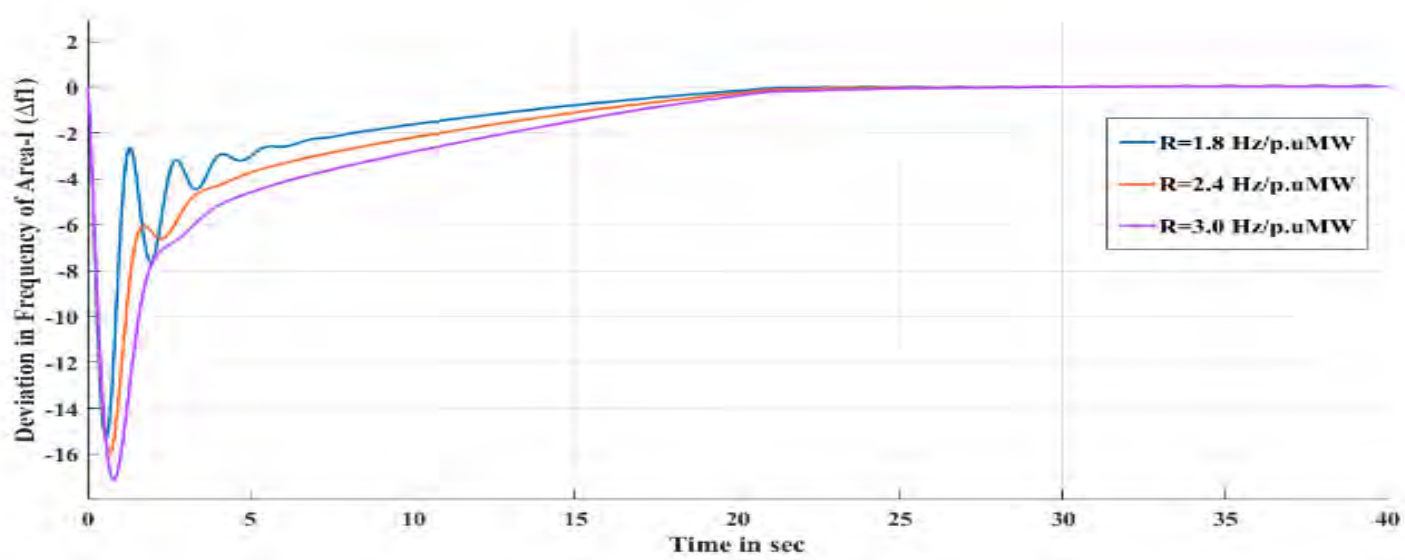

(a) Control Area-I

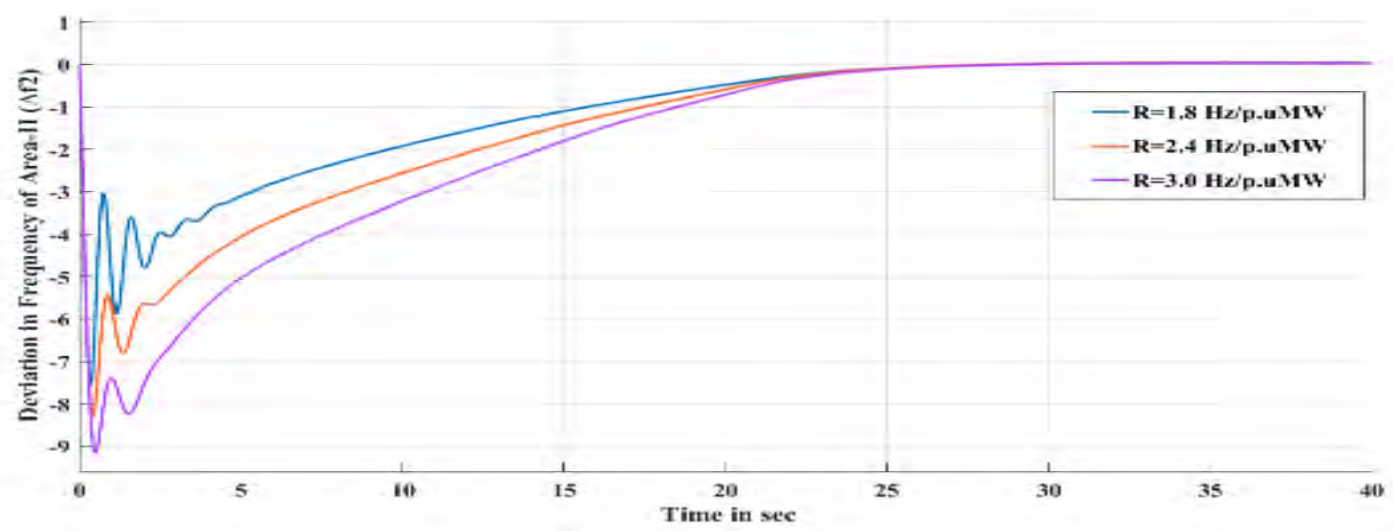

(b) Control Area-II

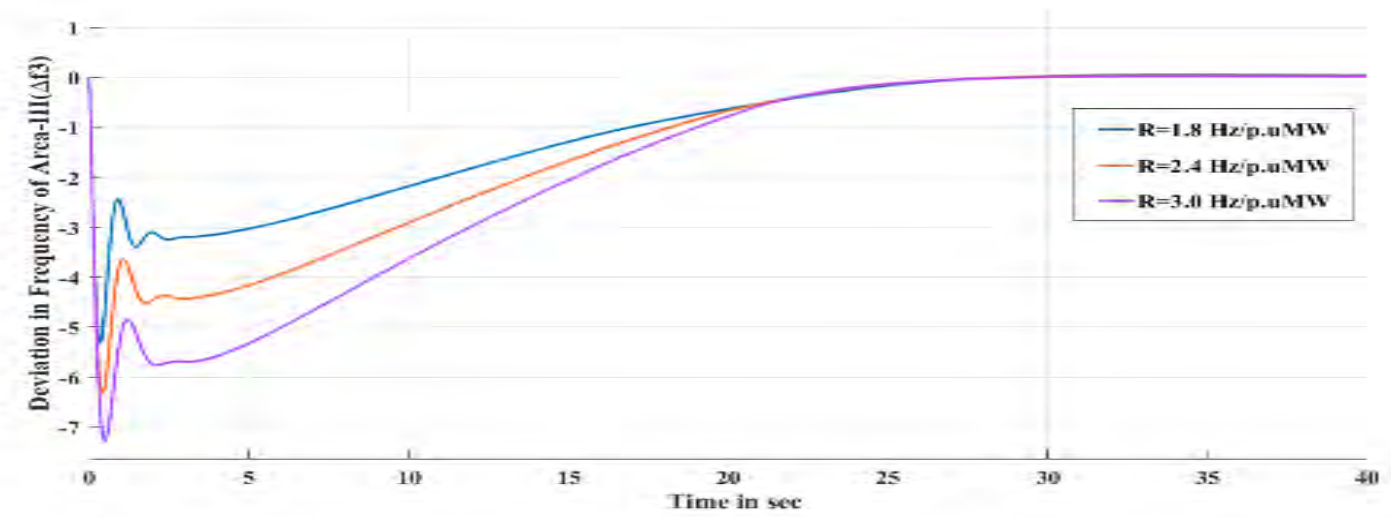

(c) Control Area-III

Figure 9: Illustrates divergence in frequency for 1\% SLP under Bilateral transaction

From figure 9, it can be said that divergence in frequency of Control Area-I, Control Area-II and Control Area-III under bilateral transaction with SLP of $1 \%$, peak overshoot and settling time for $\mathrm{R}=1.8$ is less compared to 
$\mathrm{R}=2.4$ and for $\mathrm{R}=2.4$ is less compared $\mathrm{R}=3.0$.

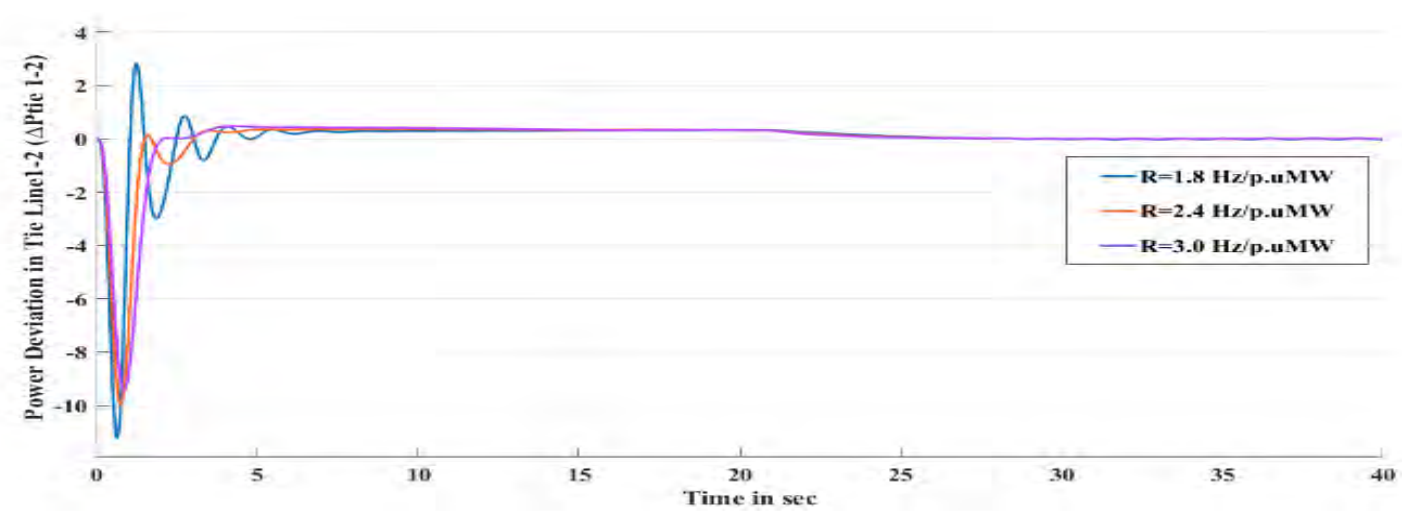

(a) Tie-Line1-2

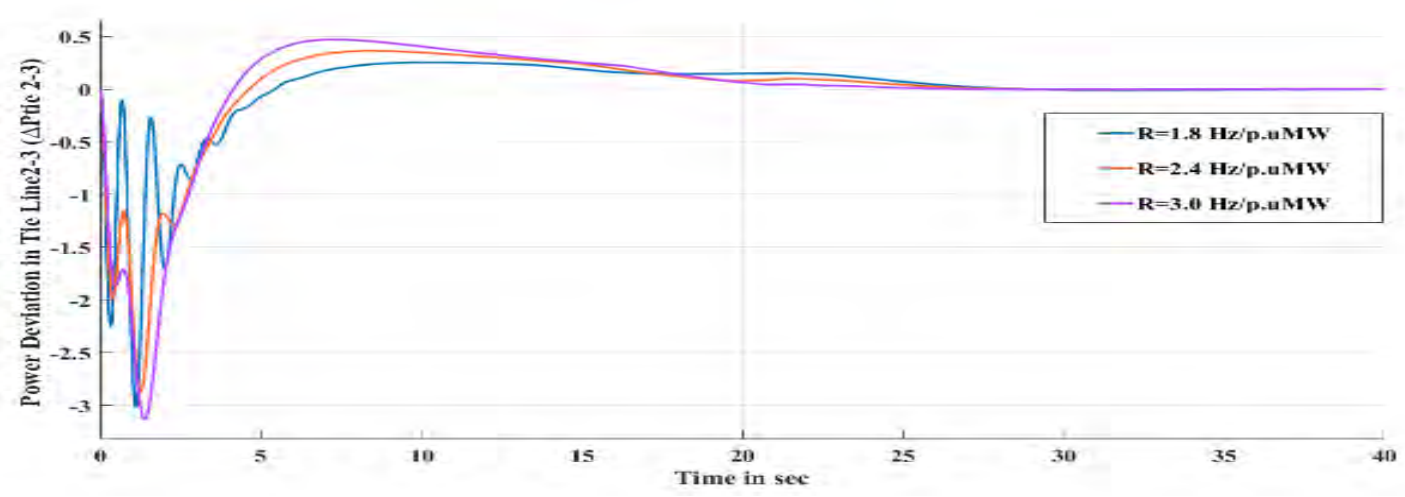

(b) Tie-Line2-3

Figure 10: Illustrates Tie-Line power divergence for 1\% SLP under Bilateral transaction

From figure 10, it can be analysed that under bilateral transaction with SLP of 1\%, for power divergence in Tie-Line1-2, peak overshoot for $\mathrm{R}=1.8$ is more compared to $\mathrm{R}=2.4$ and for $\mathrm{R}=2.4$ is more compared $\mathrm{R}=3.0$ whereas settling time for $\mathrm{R}=1.8$ is less compared to $\mathrm{R}=2.4$ and for $\mathrm{R}=2.4$ is less compared $\mathrm{R}=3.0$ and for power divergence in Tie-Line2-3, peak overshoot and settling time for $\mathrm{R}=1.8$ is less compared to $\mathrm{R}=2.4$ and for $\mathrm{R}=2.4$ is less compared $\mathrm{R}=3.0$. 
CASE B: Step load perturbations (SLP) of $10 \%$

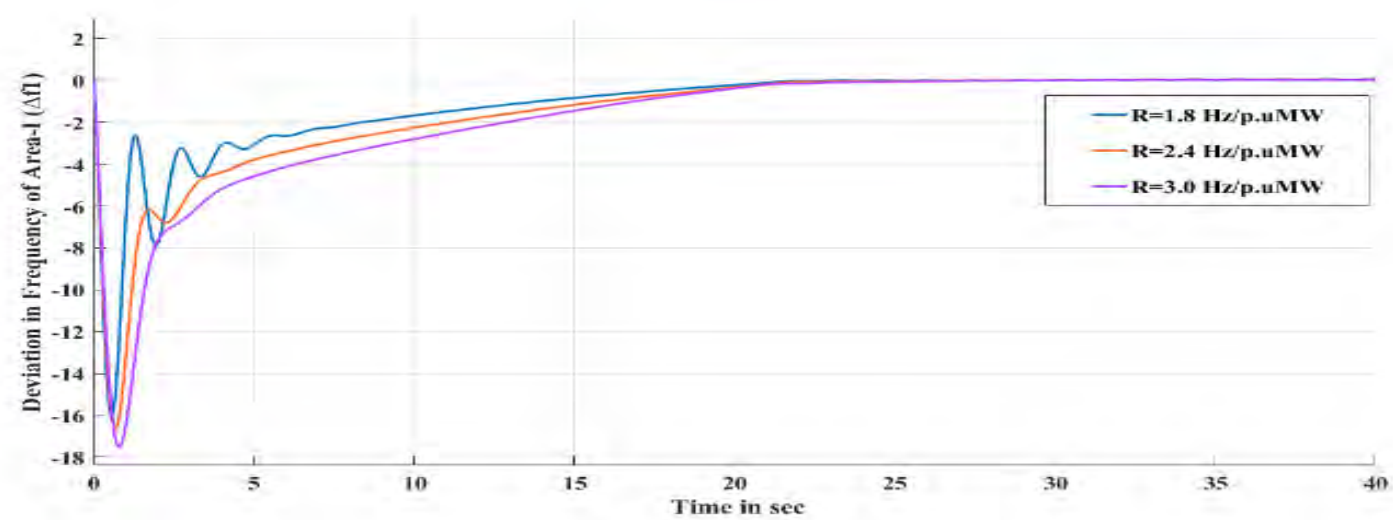

(a) Control Area-I

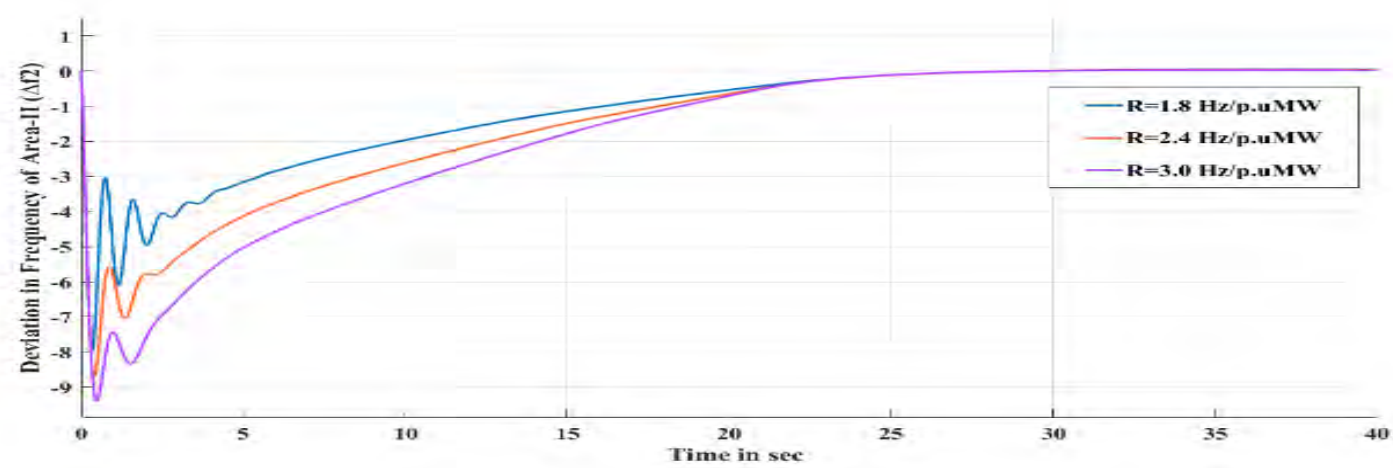

(b) Control Area-II

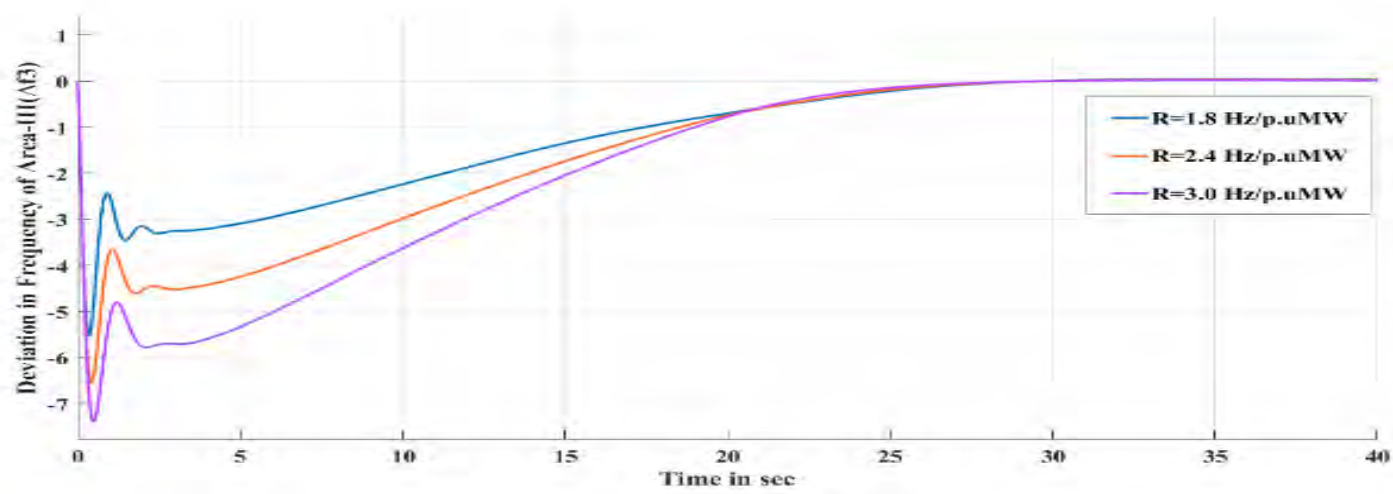

(c) Control Area-III

Figure 11: Illustrates divergence in frequency for 10\% SLP under Bilateral transaction

From figure 11, it can be said that divergence in frequency of Control Area-I, Control Area-II and Control Area-III under bilateral transaction with SLP of $10 \%$, peak overshoot and settling time for $\mathrm{R}=1.8$ is less compared to $\mathrm{R}=2.4$ and for $\mathrm{R}=2.4$ is less compared $\mathrm{R}=3.0$. 


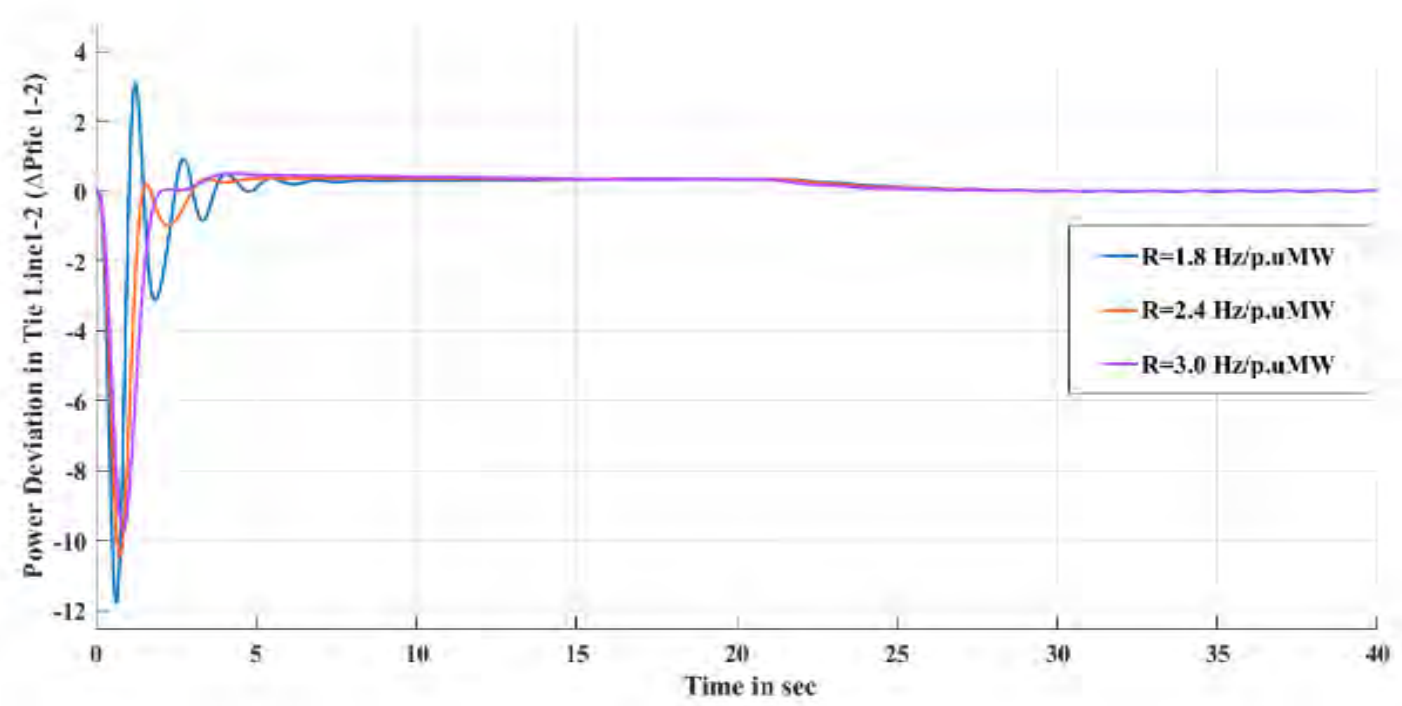

(a) Tie-Line1-2

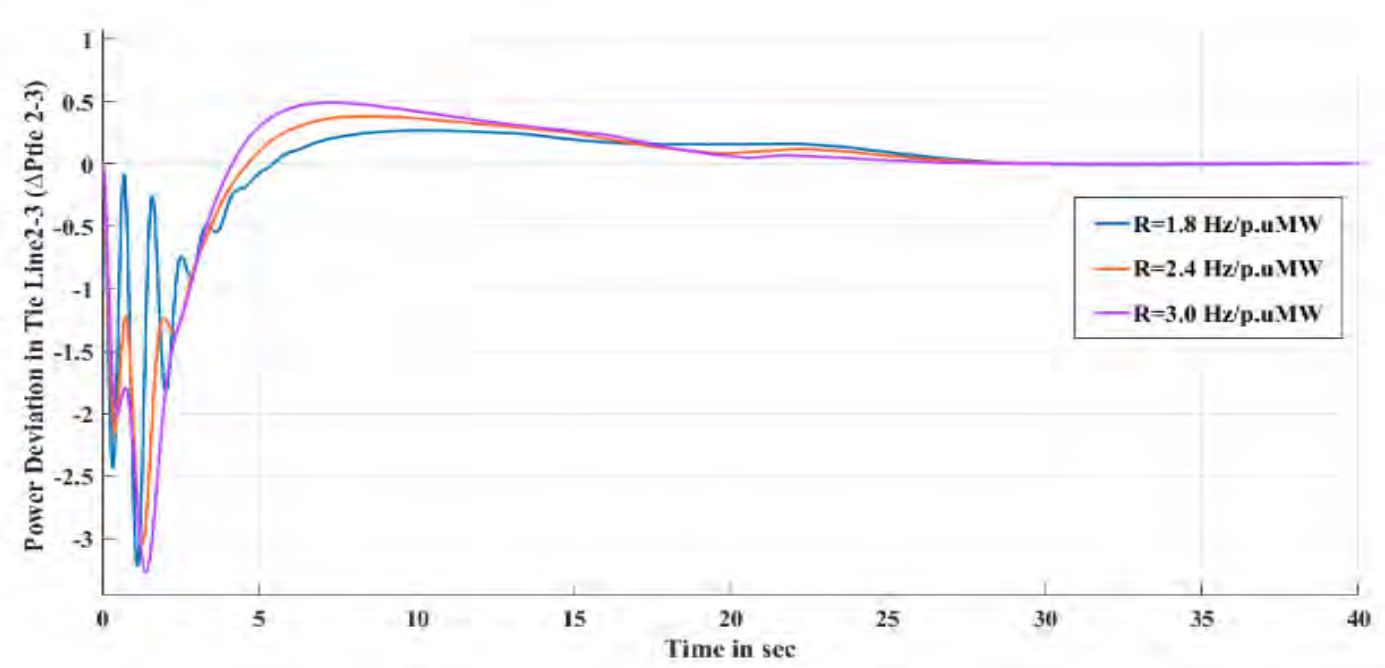

(b) Tie-Line2-3

Figure 12: Illustrates Tie-Line power divergence for 10\% SLP under Bilateral transaction

From figure 12, it can be analysed that under bilateral transaction with SLP of $10 \%$, for power divergence in Tie-Line1-2, peak overshoot for $\mathrm{R}=1.8$ is more compared to $\mathrm{R}=2.4$ and for $\mathrm{R}=2.4$ is more compared $\mathrm{R}=3.0$ whereas settling time for $\mathrm{R}=1.8$ is less compared to $\mathrm{R}=2.4$ and for $\mathrm{R}=2.4$ is less compared $\mathrm{R}=3.0$ and for power divergence in Tie-Line2-3, peak overshoot and settling time for $\mathrm{R}=1.8$ is less compared to $\mathrm{R}=2.4$ and for $\mathrm{R}=2.4$ is less compared $\mathrm{R}=3.0$. 
Table1: Assessment of dynamic parameters for three area multi-unit LFC of deregulated power system model for bilateral transaction scenario

\begin{tabular}{|c|c|c|c|c|c|}
\hline Parameter & $\begin{array}{c}\text { Regulation } \\
\text { constant }\end{array}$ & \multicolumn{2}{|c|}{ SLP=1\% } & \multicolumn{2}{c|}{ SLP=10\% } \\
\cline { 2 - 6 } & $\begin{array}{c}\text { Peak } \\
\text { overshoot }\end{array}$ & $\begin{array}{c}\text { Settling } \\
\text { time }\end{array}$ & $\begin{array}{c}\text { Peak } \\
\text { overshoot }\end{array}$ & $\begin{array}{c}\text { Settling } \\
\text { time }\end{array}$ \\
\hline \multirow{3}{*}{$\Delta \mathrm{f}_{1}$} & $\mathrm{R}=1.8$ & -2.6 & 21 & -2.8 & 22 \\
\cline { 2 - 6 } & $\mathrm{R}=2.4$ & -6.2 & 21.5 & -6.2 & 22.2 \\
\cline { 2 - 6 } & $\mathrm{R}=3.0$ & -7.2 & 22 & -7.6 & 22.4 \\
\hline \multirow{3}{*}{$\Delta \mathrm{f}_{2}$} & $\mathrm{R}=1.8$ & -3.2 & 27 & -3.2 & 28 \\
\cline { 2 - 6 } & $\mathrm{R}=2.4$ & -5.8 & 27.3 & -5.9 & 28.2 \\
\cline { 2 - 6 } & $\mathrm{R}=3.0$ & -7.8 & 27.4 & -7.8 & 28.5 \\
\hline \multirow{3}{*}{$\Delta \mathrm{f}_{3}$} & $\mathrm{R}=1.8$ & -2.4 & 27.5 & -2.4 & 28.8 \\
\cline { 2 - 6 } & $\mathrm{R}=2.4$ & -3.8 & 28 & -3.9 & 28.9 \\
\cline { 2 - 6 } & $\mathrm{R}=3.0$ & -4.8 & 28.3 & -4.9 & 29.1 \\
\hline \multirow{3}{*}{$\Delta \mathrm{P}_{\text {tie1-2 }}$} & $\mathrm{R}=1.8$ & 2.8 & 26 & 3 & 27 \\
\cline { 2 - 6 } & $\mathrm{R}=2.4$ & 0.4 & 26.3 & 0.4 & 27.3 \\
\cline { 2 - 6 } & $\mathrm{R}=3.0$ & 0.2 & 26.7 & 0.3 & 27.6 \\
\hline \multirow{3}{*}{$\Delta \mathrm{P}_{\text {tie2-3 }}$} & $\mathrm{R}=1.8$ & -0.25 & 28.1 & -0.26 & 28.5 \\
\cline { 2 - 6 } & $\mathrm{R}=2.4$ & -1.2 & 28.5 & -1.3 & 28.8 \\
\cline { 2 - 6 } & $\mathrm{R}=3.0$ & -1.7 & 28.7 & -1.8 & 29 \\
\hline
\end{tabular}

From Table 1 for bilateral contract scenarios, for various simulation conditions such as with $1 \%$ SLP and using regulation constant of 1.8, 2.4 and $3.0 \mathrm{~Hz} / \mathrm{p} . u \mathrm{MW}$, dynamic parameters in view of peak overshoot and settling time have been used for analysing the system performance. The system dynamic parameters reveal that the overall system performance with a regulation constant of 1.8 is better than 2.4 and whereas 2.4 is better than 3.0. Similarly, for SLP of $10 \%$, performance with regulation constant of 1.8 is better than 2.4 and 2.4 is better than 3.0.

\subsection{Scenario2: Considering unilateral transaction}

The DPM matrix for unilateral transactions is given as shown below

$$
\mathrm{DPM}=\left[\begin{array}{cccccccc}
0.5 & 0.5 & 0 & 0 & 0 & 0 & 0 & 0 \\
0.5 & 0.5 & 0 & 0 & 0 & 0 & 0 & 0 \\
0 . & 0 & 0.33 & 0.33 & 0.33 & 0 & 0 & 0 \\
0 & 0 & 0.33 & 0.33 & 0.33 & 0 & 0 & 0 \\
0 & 0 & 0.33 & 0.33 & 0.33 & 0 & 0 & 0 \\
0 & 0 & 0 & 0 & 0 & 0.33 & 0.33 & 0.33 \\
0 & 0 & 0 & 0 & 0 & 0.33 & 0.33 & 0.33 \\
0 & 0 & 0 & 0 & 0 & 0.33 & 0.33 & 0.33
\end{array}\right]
$$

The simulation results of divergence in frequency of control areas and Tie-Lines power divergence for different regulation constants of different Step load perturbations (SLP's) are shown below. 
CASE A: Step load perturbations (SLP) of 1\%

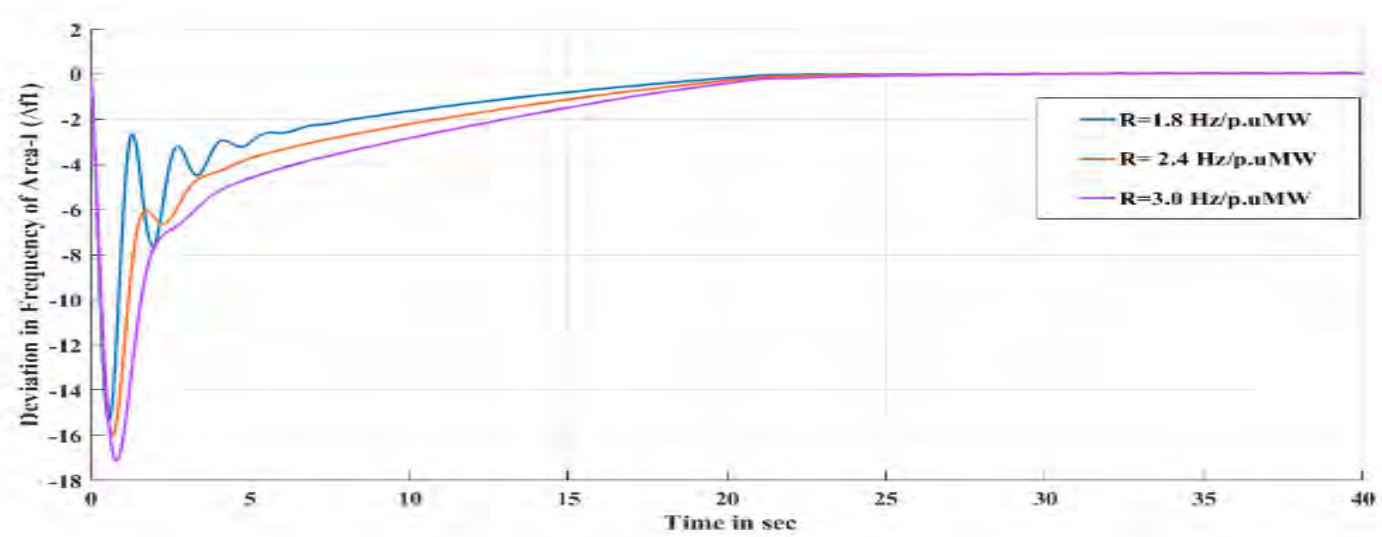

(a) Control Area-I

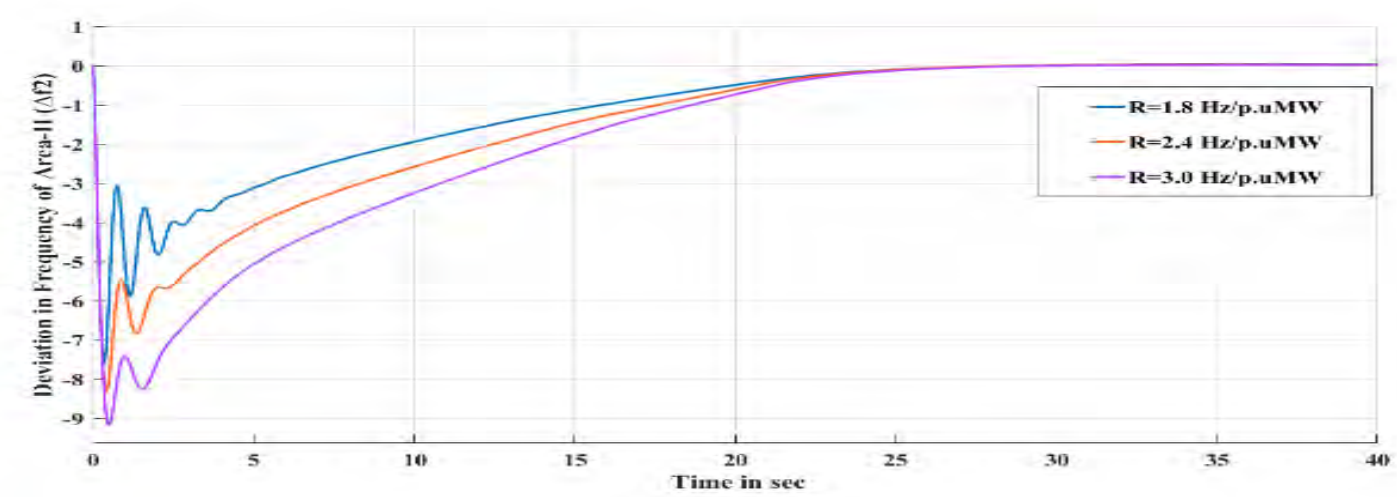

(b) Control Area-II

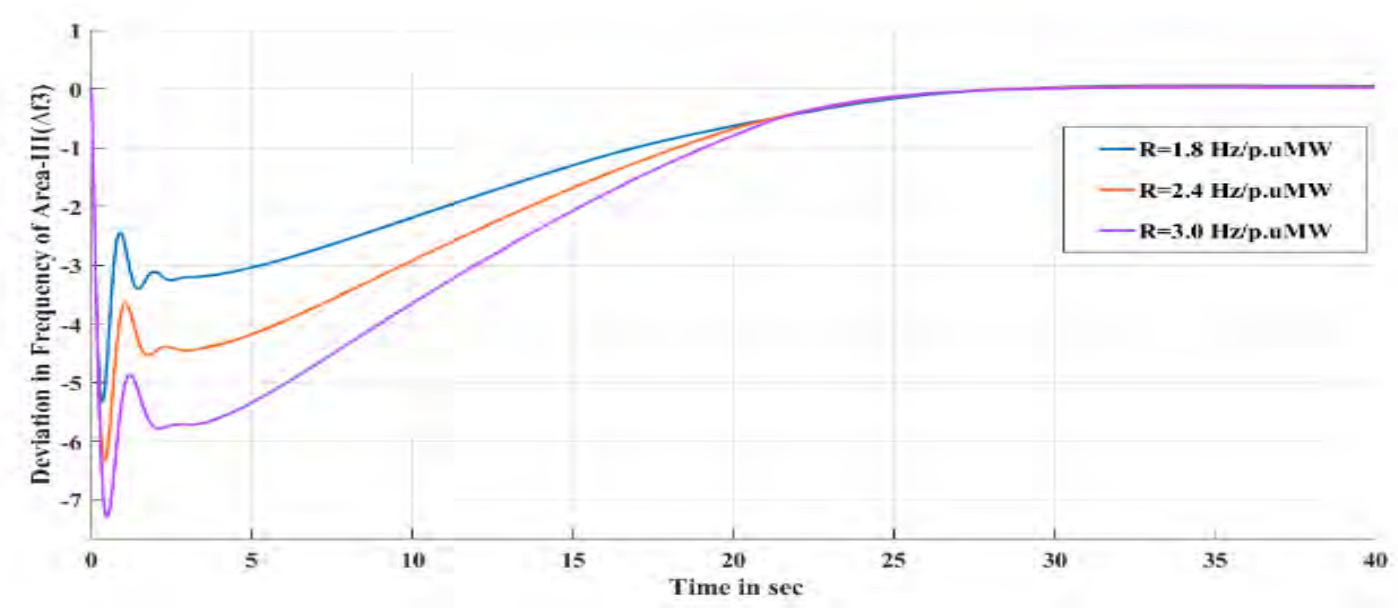

(c) Control Area-III

Figure 13: Illustrates divergence in frequency for 1\% SLP under Unilateral transaction

From figure 13, it can be said that divergence in frequency of Control Area-I, Control Area-II and Control Area-III under unilateral transaction with SLP of $1 \%$, peak overshoot and settling time for $\mathrm{R}=1.8$ is less compared to $\mathrm{R}=2.4$ and for $\mathrm{R}=2.4$ is less compared $\mathrm{R}=3.0$. 


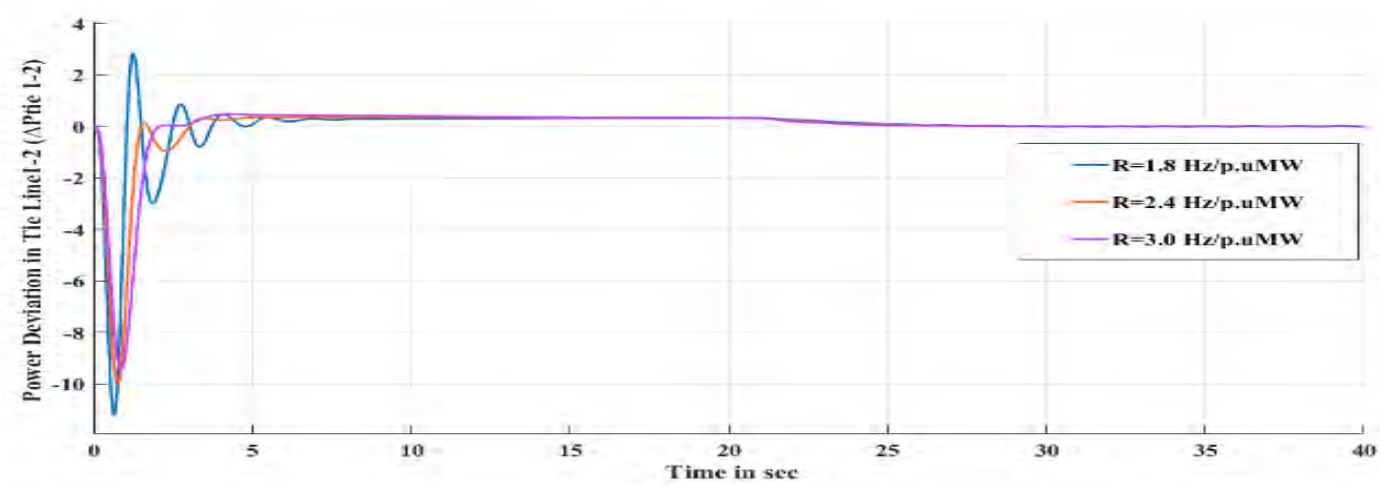

(a) Tie-Line1-2

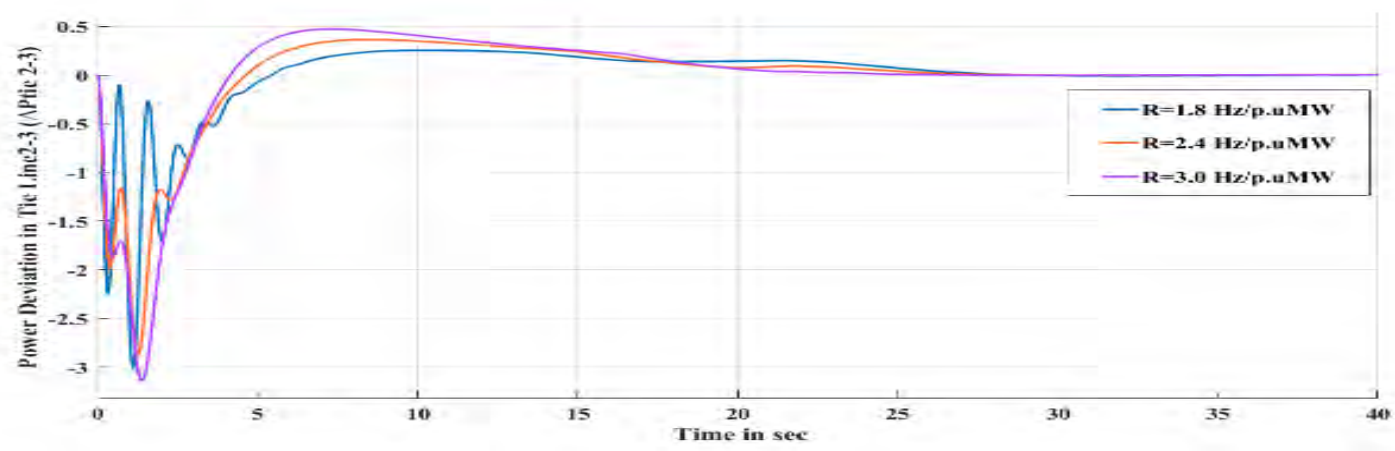

(b) Tie-Line2-3

Figure 14: Illustrates Tie-Line power divergence for 1\% SLP under Unilateral transaction

From figure 14, it can be analysed that under unilateral transaction with SLP of 1\%, for power divergence in Tie-Line1-2, peak overshoot for $\mathrm{R}=1.8$ is more compared to $\mathrm{R}=2.4$ and for $\mathrm{R}=2.4$ is more compared $\mathrm{R}=3.0$ whereas settling time for $\mathrm{R}=1.8$ is less compared to $\mathrm{R}=2.4$ and for $\mathrm{R}=2.4$ is less compared $\mathrm{R}=3.0$ and for power divergence in Tie-Line2-3, peak overshoot and settling time for $\mathrm{R}=1.8$ is less compared to $\mathrm{R}=2.4$ and for $\mathrm{R}=2.4$ is less compared $\mathrm{R}=3.0$.

CASE B: Step load perturbations (SLP) of 10\%

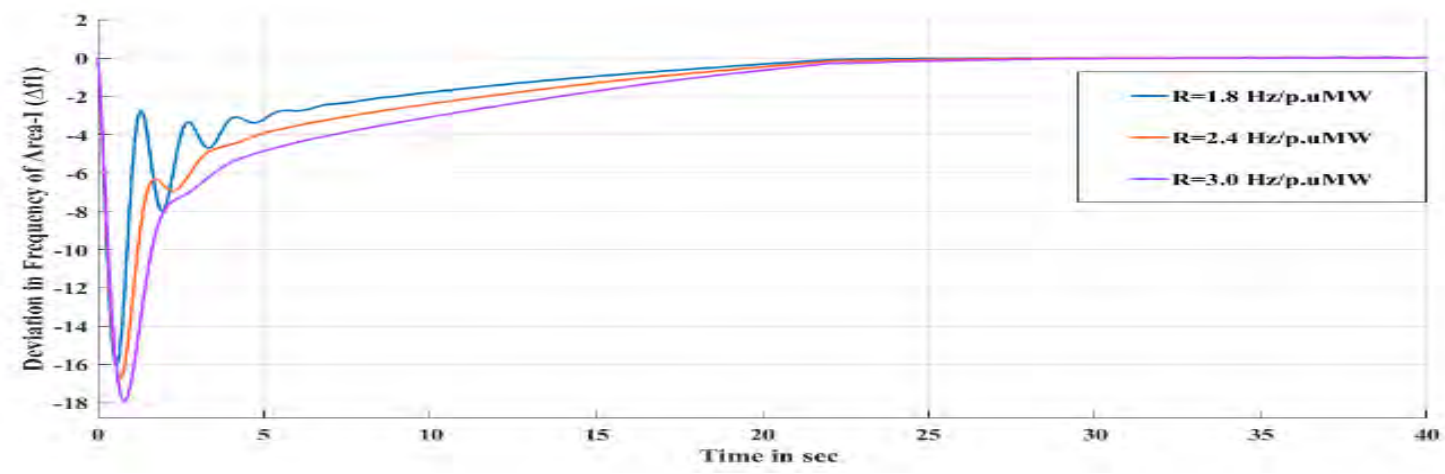

(a) Control Area-I 


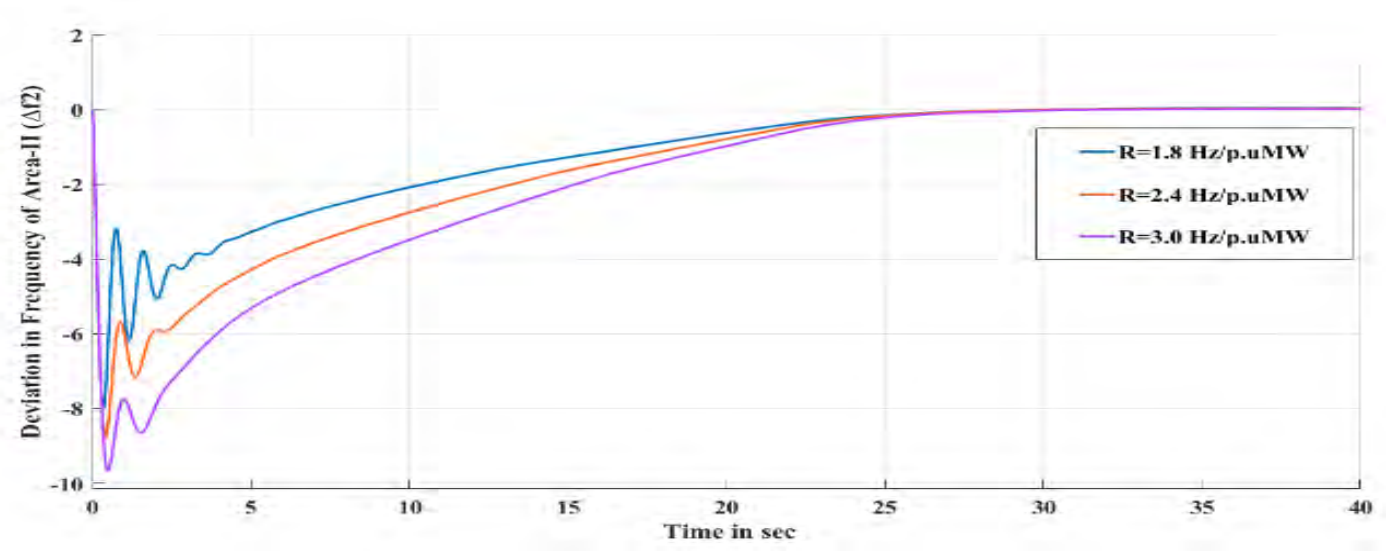

(b) Control Area-II

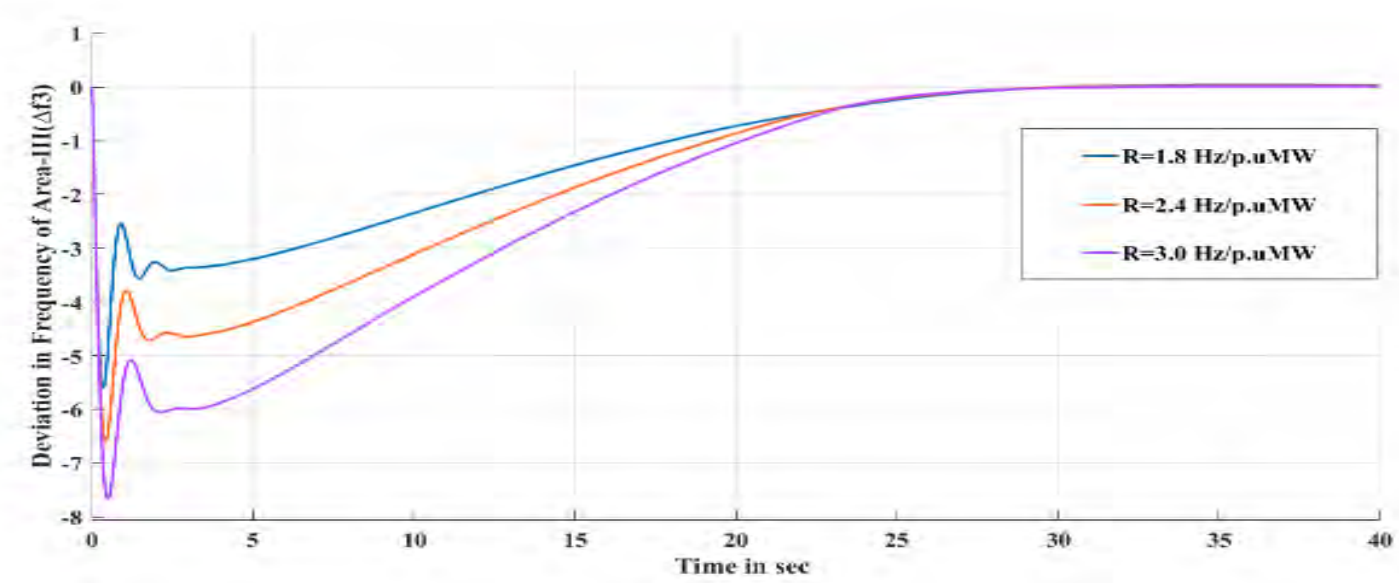

(c) Control Area-III

Figure 15: Illustrates divergence in frequency for 10\% SLP under Unilateral transaction

From figure 15, it can be said that divergence in frequency of Control Area-I, Control Area-II and Control Area-III under unilateral transaction with SLP of $10 \%$, peak overshoot and settling time for $\mathrm{R}=1.8$ is less compared to $\mathrm{R}=2.4$ and for $\mathrm{R}=2.4$ is less compared $\mathrm{R}=3.0$.

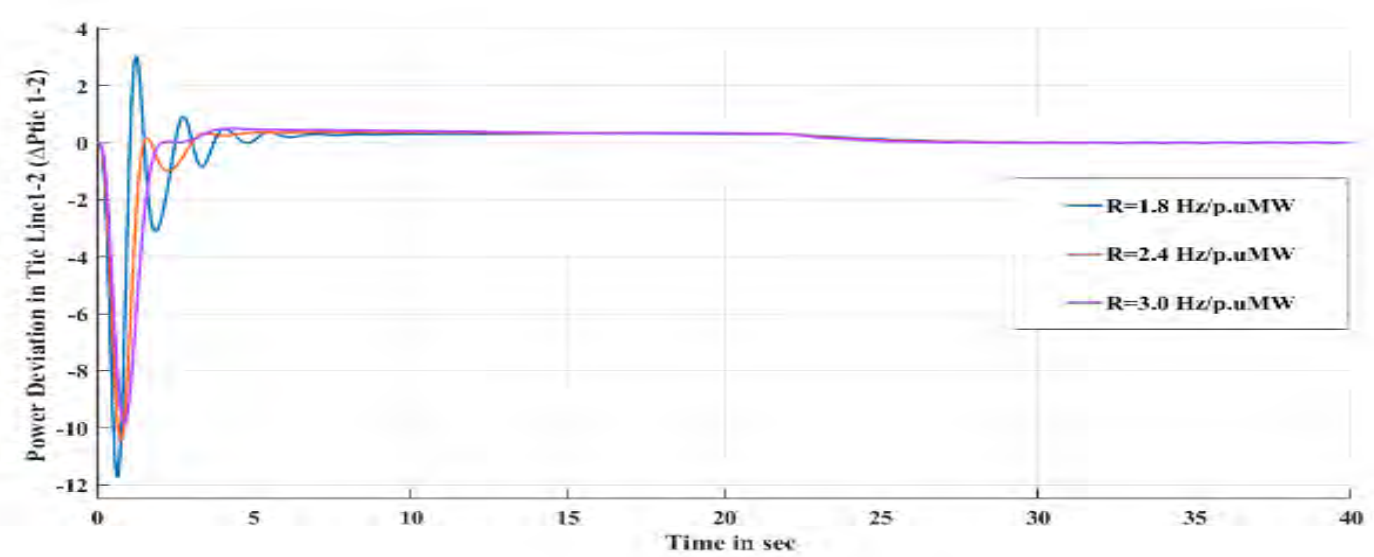

(a) Tie-Line1-2 


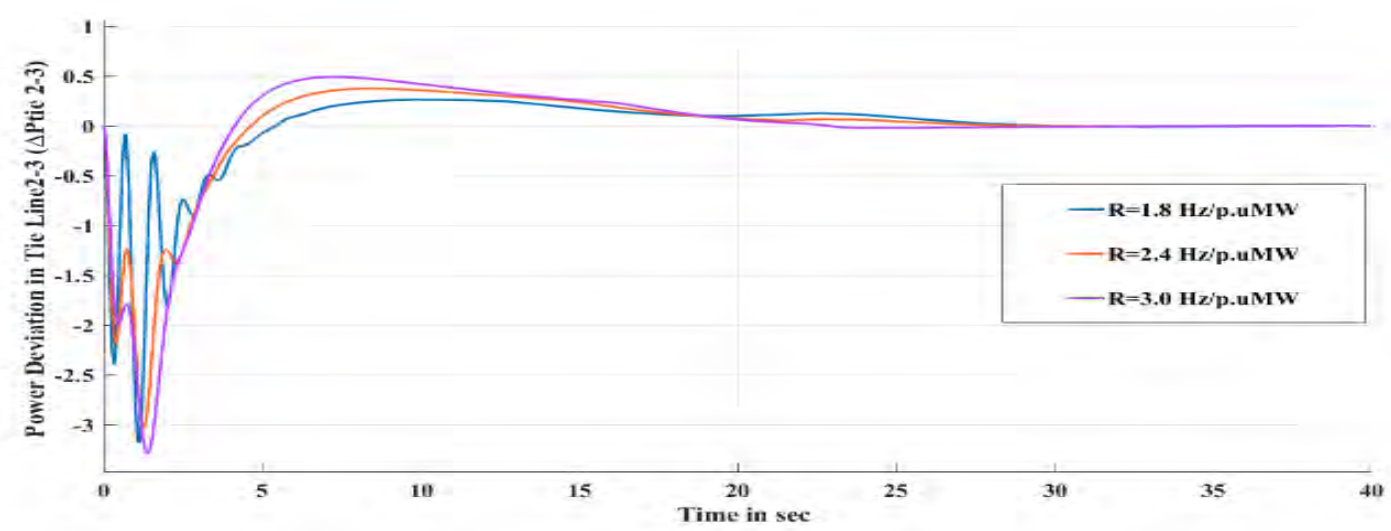

(b) Tie-Line2-3

Figure 16: Illustrates Tie-Line power divergence for 10\% SLP under Unilateral transaction

From figure 16, it can be analysed that under unilateral transaction with SLP of $10 \%$, for power divergence in Tie-Line1-2, peak overshoot for $\mathrm{R}=1.8$ is more compared to $\mathrm{R}=2.4$ and for $\mathrm{R}=2.4$ is more compared $\mathrm{R}=3.0$ whereas settling time for $\mathrm{R}=1.8$ is less compared to $\mathrm{R}=2.4$ and for $\mathrm{R}=2.4$ is less compared $\mathrm{R}=3.0$ and for power divergence in Tie-Line2-3, peak overshoot and settling time for $\mathrm{R}=1.8$ is less compared to $\mathrm{R}=2.4$ and for $\mathrm{R}=2.4$ is less compared $\mathrm{R}=3.0$.

Table 2: Assessment of dynamic parameters for three area multi-unit LFC deregulated power system model for unilateral transaction scenario

\begin{tabular}{|c|l|c|c|c|c|}
\hline Parameter & Regulation & \multicolumn{2}{|c|}{ SLP=1\% } & \multicolumn{2}{c|}{ SLP=10\% } \\
\cline { 2 - 6 } & constant & $\begin{array}{c}\text { Peak } \\
\text { overshoot }\end{array}$ & $\begin{array}{c}\text { Settling } \\
\text { time }\end{array}$ & $\begin{array}{c}\text { Peak } \\
\text { overshoot }\end{array}$ & $\begin{array}{c}\text { Settling } \\
\text { time }\end{array}$ \\
\hline \multirow{4}{*}{$\Delta \mathrm{f}_{1}$} & $\mathrm{R}=1.8$ & -2.6 & 21.5 & -2.9 & 22.1 \\
\cline { 2 - 6 } & $\mathrm{R}=2.4$ & -6.2 & 22 & -6.4 & 22.3 \\
\cline { 2 - 6 } & $\mathrm{R}=3.0$ & -7.4 & 22.2 & -7.8 & 22.6 \\
\hline \multirow{4}{*}{$\Delta \mathrm{f}_{2}$} & $\mathrm{R}=1.8$ & -3.4 & 27.2 & -3.2 & 28.2 \\
\cline { 2 - 6 } & $\mathrm{R}=2.4$ & -5.8 & 27.4 & -5.9 & 28.4 \\
\cline { 2 - 6 } & $\mathrm{R}=3.0$ & -7.8 & 27.5 & -8 & 28.7 \\
\hline \multirow{4}{*}{$\Delta \mathrm{f}_{3}$} & $\mathrm{R}=1.8$ & -2.5 & 28 & -2.6 & 28.7 \\
\cline { 2 - 6 } & $\mathrm{R}=2.4$ & -3.85 & 28.2 & -3.9 & 28.8 \\
\cline { 2 - 6 } & $\mathrm{R}=3.0$ & -4.9 & 28.3 & -5.1 & 29 \\
\hline \multirow{3}{*}{$\Delta \mathrm{P}_{\text {tie1-2 }}$} & $\mathrm{R}=1.8$ & 2.8 & 26.1 & 3.2 & 26.8 \\
\cline { 2 - 6 } & $\mathrm{R}=2.4$ & 0.4 & 26.5 & 0.42 & 27.1 \\
\cline { 2 - 6 } & $\mathrm{R}=3.0$ & 0.3 & 26.8 & 0.35 & 27.2 \\
\hline \multirow{3}{*}{$\Delta \mathrm{P}_{\text {tie2-3 }}$} & $\mathrm{R}=1.8$ & -0.2 & 28.5 & -0.25 & 29 \\
\cline { 2 - 6 } & $\mathrm{R}=2.4$ & -1.2 & 28.8 & -1.3 & 28.5 \\
\cline { 2 - 6 } & $\mathrm{R}=3.0$ & -1.7 & 28.9 & -1.8 & 28 \\
\hline
\end{tabular}

From Table 2 for unilateral contract scenarios, for various simulation conditions such as with $1 \%$ SLP and using regulation constant of 1.8, 2.4 and $3.0 \mathrm{~Hz} /$ p.uMW, dynamic parameters in view of peak overshoot and settling 
time have been used for analysing the system performance. The system dynamic parameters reveal that the overall system performance with a regulation constant of 1.8 is better than 2.4 and whereas 2.4 is better than 3.0. Similarly, for SLP of $10 \%$, performance with regulation constant of 1.8 is better than 2.4 and 2.4 is better than 3.0. But unilateral contract scenario dynamic parameters values are higher than bilateral contract scenario.

\section{CONCLUSION}

In this paper, FOSMC is used with the integration of TCPS-SMES to control load frequency for three area multi-unit deregulated power system. For bilateral contract scenarios, for various simulation conditions such as with 1\% SLP and using regulation constant of 1.8, 2.4 and $3.0 \mathrm{~Hz} / \mathrm{p} . \mathrm{uMW}$, dynamic parameters in view of peak overshoot and settling time have been used for analyzing the system performance The system dynamic parameters reveal that the performance with a regulation constant of 1.8 is better than 2.4 and whereas 2.4 is better than 3.0. Similarly, for SLP of $10 \%$, performance with regulation constant of 1.8 is better than 2.4 and 2.4 is better than 3.0. Comparatively similar results obtained for unilateral contract scenario, but unilateral contract scenario dynamic parameters values are higher than bilateral contract scenario.

\section{Acknowledgements}

I wish to take this opportunity to express my deep sense of gratitude and thanks to all the people behind the screen who helped me to transform an idea into a real application. I wish to express my heart-felt gratitude to my parents without whom I would not have been privileged to achieve and fulfill my dreams. I would like express my sincere gratitude and indebtedness to Dr.G. V. Nagesh Kumar, Prof. \& Head, Dr. V. Ganesh, Professor in charge examinations \& Professor, Sri. S. Hussain Valli, Assistant Professor, Department of Electrical and Electronics Engineering, JNTUACEP, Pulivendula, Andhra Pradesh, India for their valuable suggestions.

\section{REFERENCES}

[1] N. Bekhouche, Automatic generation control before and after deregulation, in: Proceedings of the Thirty-Fourth Southeastern Symposium on System Theory (Cat. No. 02EX540), IEEE, pp. 321-323, 2002.

[2] H. Bevrani, Y. Mitani, K. Tsuji, Robust agc: Traditional structure versus restructured scheme, IEEEJ Transactions on Power and Energy 124 (5) 751-761, 2004.

[3] H. Shayeghi, H. Shayanfar, A. Jalili, LFC design of a deregulated power system with tcps using pso, International Journal of Electrical and Electronics Engineering 3 (10) 632-640, 2009.

[4] R. J. Abraham, D. Das, A. Patra, Automatic generation control of an interconnected hydrothermal power system considering 
superconducting magnetic energy storage, International Journal of Electrical Power \& Energy Systems 29 (8) 571-579, 2007.

[5] A. Pappachen, A. P. Fathima, Load frequency control in deregulated power system integrated with smes-tcps combination using anfis controller, International Journal of Electrical Power \& Energy Systems 82 519-534, 2016.

[6] M. Deepak, Analysis of tcps-smes coordination in a multi area thermal system with automatic generation control, in: 2014 International Conference on Circuits, Power and Computing Technologies [ICCPCT-2014], IEEE, pp. 612-615, 2014.

[7] C. Yin, Y. Chen, S.-m. Zhong, Fractional-order sliding mode-based extremum seeking control of a class of nonlinear systems, Automatica 50 (12) 3173-3181, 2014.

[8] K. G. Ravikumar, B. Bosley, T. Clark, J. Garcia, Generation control system: Using isochronous load-sharing principles with gas and steam turbine generators, IEEE Industry Applications Magazine 25 (2) 36-44, 2018.

[9] H. Bevrani, Decentralized robust load-frequency control synthesis in restructured power systems, PhD Thesis, Osaka University, 2004. 